\title{
Detection of stanozolol in environmental waters using liquid chromatography tandem mass spectrometry
}

\author{
Nawed IK Deshmukh" ${ }^{*}$, James Barker ${ }^{1}$, Andrea Petroczi ${ }^{2}$ and Declan P Naughton ${ }^{2}$
}

\begin{abstract}
Background: Owing to frequent administration of a wide range of pharmaceutical products, various environmental waters have been found to be contaminated with pharmacologically active substances. For example, stanozolol, a synthetic anabolic steroid, is frequently misused for performance enhancement as well as for illegal growth promoting purposes in veterinary practice. Previously we reported stanozolol in hair samples collected from subjects living in Budapest. For this reason we initiated this study to explore possible environmental sources of steroid contamination. The aim of this study was to develop a method to monitor stanozolol in aqueous matrices using liquid chromatography tandem mass spectrometry (LC-MS/MS).

Results: Liquid-liquid extraction using pentane was found to be an efficient method for the extraction of stanozolol from water samples. This was followed by direct detection using LC-MS/MS. The method was capable of detecting $0.25 \mathrm{pg} / \mathrm{mL}$ stanozolol when only $5 \mathrm{~mL}$ water was processed in the presence of stanozolol D3 as internal standard. Fifteen bottled waters analysed were found to be negative for stanozolol. However, three out of six samples from the Danube river, collected from December '09 to November '10, were found to contain stanozolol at concentrations up to $1.82 \mathrm{pg} / \mathrm{mL}$. In contrast, only one sample (out of six) of urban tap water from Budapest city was found to contain stanozolol, at a concentration of $1.19 \mathrm{pg} / \mathrm{mL}$.
\end{abstract}

Conclusion: The method developed is efficient, rapid, reproducible, sensitive and robust for the detection of stanozolol in aqueous matrices.

\section{Background}

Regular and widespread use of pharmaceuticals, which are frequently excreted as non- metabolized parent compounds, has led to growing concerns for the safety of drinking water [1]. The vast range of pharmaceutical products that have been detected in sewage, surface, ground and drinking waters include bronchodilators, oral contraceptives, antidepressants, beta-blockers, antibiotics, anti-inflammatories and analgesics [2-7]. Even modern sewage treatment works are not constructed to specifically eliminate pharmaceuticals [1] from potable water supplies.

Stanozolol, an anabolic steroid is a synthetic derivative of the endogenously-produced male-sex hormone testosterone. It is commonly misused as a performance

\footnotetext{
* Correspondence: K0630928@kingston.ac.uk

${ }^{1}$ School of Pharmacy and Chemistry, Kingston University, London, UK

Full list of author information is available at the end of the article
}

enhancement drug because of its ability to enhance muscular strength. The World Anti-Doping Agency (WADA) has banned its use in- and out-of-competition [8]. Despite the restriction, stanozolol is one of the most commonly misused synthetic, anabolic steroids in sport [9] and in veterinary practice, where it is used for growth promoting purposes [10].

In humans, stanozolol is mainly metabolized by undergoing hydroxylation to form mono- and di-hydroxylated metabolites. The majority of these are excreted in urine in the form of conjugates. Less than $5 \%$ are excreted as non-conjugated fractions [10]. According to WADA, doping with stanozolol is confirmed if the urinary concentration of its major metabolite, 3-hydroxystanozolol exceeds $2 \mathrm{ng} / \mathrm{mL}$ [11]. Unlike testosterone, the synthetic stanozolol and/or its main metabolite should only appear in environmental waters if the former is used for veterinary purposes, taken under medical 
supervision or illegally by athletes for performance enhancement or if either one or both of these compounds are accidently discharged into environmental waters. In previous studies, we reported the detection of stanozolol in hair samples collected from subjects living in Budapest [12,13]. For this reason, we initiated this study to explore possible environmental sources of steroid contamination.

The aim of this study was to develop a methodology for the detection of stanozolol in aqueous matrices. To achieve this, liquid - liquid extraction (LLE) was employed for purification and concentration followed by direct determination using LC-MS/MS. Extraction recovery was evaluated for aqueous matrices spiked with stanozolol at $\mathrm{pg} / \mathrm{mL}$ levels.

\section{Experimental}

\section{Reagents and chemicals}

Stanozolol and stanozolol D3 (internal standard) were obtained from LGC standards (Teddington, London, UK). Pentane, deionised water, formic acid, and acetonitrile were obtained from Sigma Aldrich (Poole, Dorset, UK). All chemicals and reagents were of HPLC grade. Environmental water samples were obtained from Budapest (Hungary) and collected from the River Danube and an urban tap (drinking water) in clean, amber bottles. Water samples were collected periodically from December 2009 to November 2010. Samples from Lake Balaton and spring water (Rózsika forrás, Solymár, near Budapest) were also collected for comparison. Some commonly-consumed, bottled non-carbonated, natural mineral water samples were purchased from local supermarkets. The majority of the analysed, commercially available, bottled natural mineral waters are recognised by the European Union [14]. All water samples were stored at $-20^{\circ} \mathrm{C}$ and protected from light prior to analysis.

\section{Extraction procedure}

Liquid-liquid extraction (LLE) using pentane was employed for the extraction of stanozolol from water samples. Suspended particles were not filtered from the river water so that the drug adsorbed on them could also be extracted efficiently. A $5 \mathrm{~mL}$ aliquot of each water sample was spiked with stanozolol D3 (internal standard, $50 \mu \mathrm{L}$ of $10 \mathrm{ng} / \mathrm{mL}$ ) [13] followed by the addition of $3 \mathrm{~mL}$ pentane. The contents were vortex mixed vigorously for 10 seconds followed by centrifugation at $3500 \times \mathrm{g}$ at ambient temperature for 5 minutes. The pentane layer was separated and collected in a silanized glass tube. To ensure good recovery, the extraction procedure was performed twice. Both organic fractions were pooled and dried by evaporation at $45{ }^{\circ} \mathrm{C}$ under a gentle stream of nitrogen gas. The dried residue was then reconstituted with $50 \mu \mathrm{L}$ acetonitrile. A $5 \mu \mathrm{L}$ aliquot of the reconstituted solution was injected into the LC-MS/MS system for analysis.

\section{Instrumentation}

The LC-MS/MS system consisted of an Accela LC system (Thermo Scientific, UK) coupled to a TSQ Quantum triple quadrupole mass spectrometer (Thermo electron, UK) without a flow splitter. The LC system was comprised of a quaternary pump, automatic solvent degasser, column heater and an auto-sampler equipped with tray chiller. Chromatographic separation was obtained on an Agilent Zorbax SB-C18 column $(2.1 \mathrm{~mm}$ $\times 50 \mathrm{~mm}, 1.8 \mu \mathrm{m})$ maintained at $60{ }^{\circ} \mathrm{C}$. Water and acetonitrile both containing $0.1 \%$ formic acid were used as mobile phase solvents. The total flow rate through the column was $100 \mu \mathrm{L} /$ minute. The gradient flow composition is shown in Table 1.

The mass spectrometer was equipped with an electrospray ionization (ESI) source operated in positive ion mode. The capillary temperature was maintained at 350 ${ }^{\circ} \mathrm{C}$. An ion spray voltage of $4000 \mathrm{~V}$ was essential for optimum ionization of stanozolol and stanozolol D3 (internal standard). The protonated molecules, $[\mathrm{M}+\mathrm{H}]^{+}$, of stanozolol $(\mathrm{m} / \mathrm{z} 329.2)$ and stanozolol D3 $(\mathrm{m} / z$ 332.2), were used as precursor ions for collision induced dissociation (CID) for MS-MS analysis. Selective reaction monitoring (SRM) was used to monitor the precursor ions and diagnostic product ions for unambiguous quantification of stanozolol. The collision energies and SRM, $m / z$ transitions for stanozolol and internal standard (I.S.) are shown in Table 2.

The Thermo Scientific Xcalibur software (version 2.1) was used to control the LC system and mass spectrometer. Data analysis and assay performance was also evaluated using the same software. The performance of the analytical method was validated for the following set of parameters: linearity, specificity, accuracy, lower limit of detection (LLOD), lower limit of quantification (LLOQ), inter-day precision and intra-day precision. Calibration samples and quality control samples at low, medium and high concentration levels were prepared by fortifying $5 \mathrm{~mL}$ HPLC grade water with known concentrations of stanozolol and I.S. followed by LLE and LC-

\section{Table 1 LC mobile phase gradient composition}

\begin{tabular}{ccc}
\hline $\begin{array}{c}\text { LC run time } \\
\text { (minutes) }\end{array}$ & $\begin{array}{c}\mathbf{0 . 1 \%} \text { Formic acid in } \\
\text { acetonitrile (\%) }\end{array}$ & $\begin{array}{c}\mathbf{0 . 1 \%} \text { Formic acid in } \\
\text { water (\%) }\end{array}$ \\
\hline 0 & 50 & 50 \\
4 & 100 & 0 \\
6.5 & 100 & 0 \\
7 & 50 & 50 \\
10 & 50 & 50 \\
\hline
\end{tabular}


Table 2 Retention times, SRM transitions and collision energies of stanozolol and stanozolol D3 (internal standard)

\begin{tabular}{cccc}
\hline Analytes & $\begin{array}{c}\text { Retention } \\
\text { time }(\mathbf{m i n})\end{array}$ & Transition $(\mathbf{m} / \mathbf{z})$ & $\begin{array}{c}\text { Collision } \\
\text { energy }(\mathbf{e V})\end{array}$ \\
\hline Stanozolol & 3.58 & $329.2 \rightarrow 81.2$ & 42 \\
Stanozolol D3 & 3.56 & $329.2 \rightarrow 121.2$ & 50 \\
\hline
\end{tabular}

MS/MS analysis. The analyte-to-internal standard ratio was calculated by dividing the area of analyte peak by the area of the I.S. peak.

A calibration curve was constructed by plotting the analyte-to-internal standard ratio versus the known concentration of stanozolol in each sample. Linear regression analysis using the least squares method was employed to evaluate the calibration curve of analyte as a function of its concentrations in water samples. The LLOQ or lowest point on the calibration curve was defined as the lowest concentration of analyte which could be quantified with a precision $<20 \%(\mathrm{CV})$. To determine the lower limit of detection (LLOD), a number of serial 1:2 dilutions were made from the low standard (LLOQ). The lowest concentration which gave a response equivalent to three times the background noise was considered as the LLOD. The accuracy and intraday precision was assessed by injecting QC samples in replicates at 3 different concentrations. This was repeated on three consecutive days to evaluate the interday precision of the assay. The average extraction recovery for the analyte was determined by comparing the analyte to internal standard peak area ratio obtained after extracting negative control water samples fortified with stanozolol at a final concentration of $2 \mathrm{pg} / \mathrm{mL}$ in presence of I.S with the un-extracted standard working solutions at the same concentrations. The matrix effects were assessed by comparing the responses of analyte and I.S. obtained from the extracted blank water samples (HPLC grade, tap water and river water) spiked with known concentrations of stanozolol and stanozolol D3 after extraction to those obtained from neat standard solution at the same final concentrations. Validation results are shown in Table 3.

\section{Results and discussion Method validation}

Stanozolol was unambiguously analysed on the basis of its SRM transition and retention time (Figures 1 and 2) via the method proposed and validated herein. Regression analysis indicated that the assay showed excellent linearity within the quantification range of 0.5 to 200 $\mathrm{pg} / \mathrm{mL}$ water for stanozolol. The LLOQ for stanozolol was found to be $0.5 \mathrm{pg} / \mathrm{mL}$. The correlation coefficients were found to be greater than 0.996 during the method validation procedure. Under the optimized LC-MS/MS conditions, the assay was capable of detecting (LLOD) stanozolol, without any interference, at a concentration as low as $0.25 \mathrm{pg} / \mathrm{mL}$ water when $5 \mathrm{~mL}$ water was processed. The analytical characteristics of this method including accuracy, linearity, LLOD, LLOQ, inter-day precision, intra-day precision and extraction recoveries from HPLC grade, river and tap water are summarized in Table 3. The relative standard deviation (RSD) was used to assess method precision and it indicated good reproducibility.

Matrix effects in river water led to a reduction in peak areas of stanozolol and stanozolol D3 by $22.3 \%$ and $18.4 \%$, respectively. Comparatively, tap water and HPLC water showed lesser matrix effects. The reduction in peak areas was possibly attributed to ion suppression in the ESI source. However, after internal standard correction, the matrix effects in all three types of water samples were comparable and in the range $95.4-97.3 \%$ as shown in Table 4. Thus, stanozolol D3 was used as an internal standard to: i) compensate for matrix induced changes in ionization of analyte, ii) correct any loss of analyte during sample preparation, iii) compensate for any variations in the instrument response from injection to injection. The absolute extraction recoveries (with I.S. correction) in three water types; namely HPLC grade water, Danube river water and tap water were in the range $95.3 \%$ to $98.4 \%$. The relative extraction recoveries (with I.S. correction) in all three water types were found to be in the range 94.2 to $95.5 \%$ for stanozolol as shown in Table 5. This indicated that the method is capable of detecting stanozolol in different types of aqueous matrix when only $5 \mathrm{~mL}$ water was processed. The analytical prerequisites for efficient detection of stanozolol at low

Table 3 Summary of assay validation results for stanozolol

\begin{tabular}{lccccc}
\hline Analytes & $\begin{array}{l}\text { Linear range } \\
(\mathbf{p g} / \mathrm{mL})\end{array}$ & $\begin{array}{c}\text { Concentration } \\
(\mathbf{p g} / \mathbf{m L})\end{array}$ & Precision RSD (\%) & Accuracy (\%) \\
\hline & & & $\begin{array}{l}\text { Intraday } \\
\mathbf{N}=\mathbf{6 + 6 + 6}\end{array}$ & $\begin{array}{l}\text { Interday } \\
\mathbf{N}=\mathbf{1 8 + 1 8 + 1 8}\end{array}$ \\
\hline Stanozolol & 0.5 to 200 & 2 & 8.5 & 7.4 & 91.7 \\
& & 16 & 3.7 & 7.8 & 100 \\
& 100 & 6.1 & 7.4 & 106.6 \\
\hline
\end{tabular}




\section{Stanozolol}
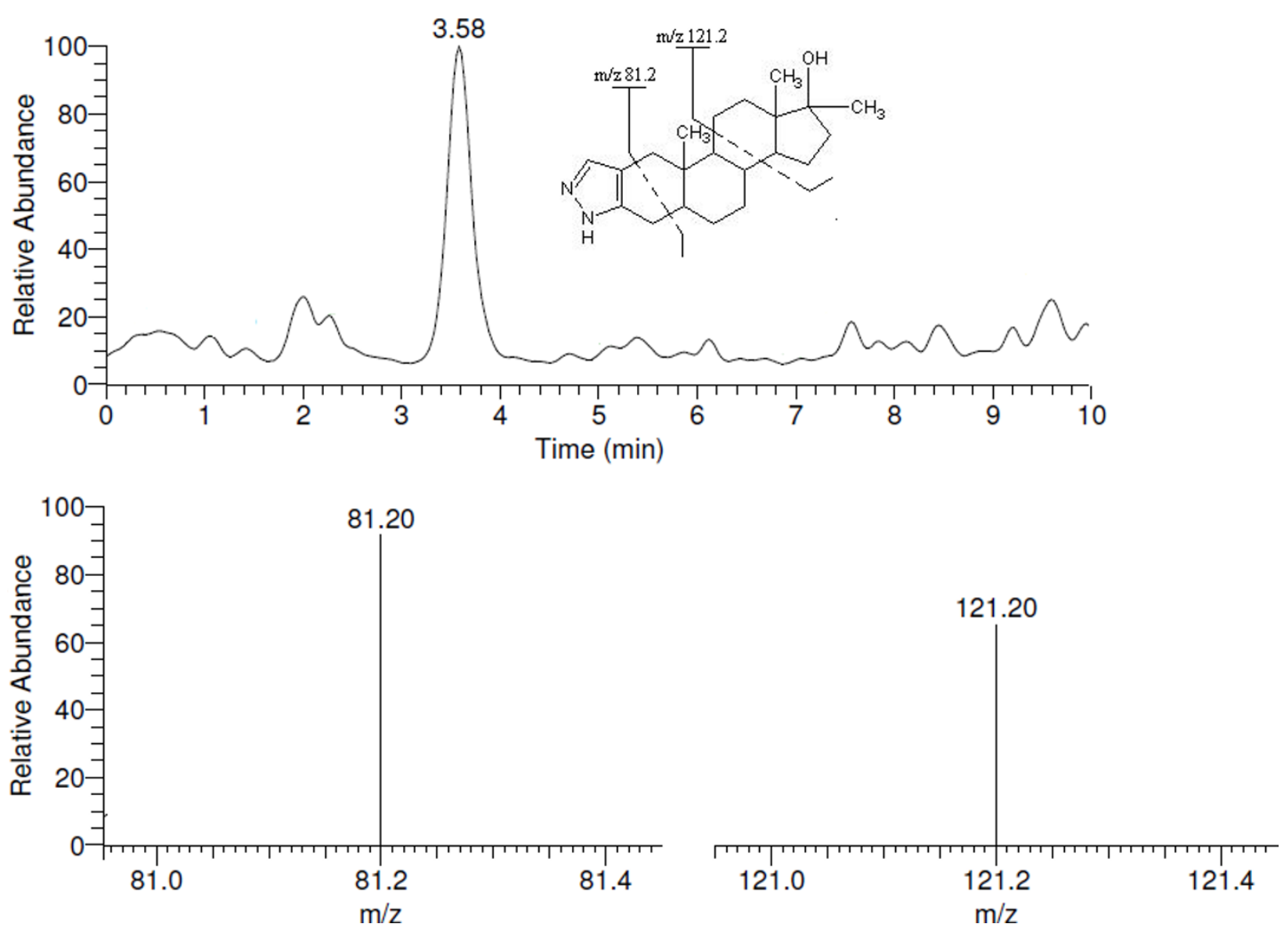

Figure 1 Chromatogram and mass spectrum of stanozolol spiked to Danube river water at a final concentration of $0.5 \mathrm{pg} / \mathrm{mL}$.

levels in aqueous matrix were, purification of water samples using liquid-liquid extraction in presence of a deuterated internal standard followed by injecting only $5 \mu \mathrm{L}$ aliquot through the column combined with the optimized LC-MS/MS conditions employed for analysis.

Gas chromatography mass spectrometry (GC-MS) and high performance liquid chromatography (HPLC) coupled to fluorescence and UV detectors have been commonly employed to analyse steroids [15]. However, HPLC coupled to fluorescence detection involves laborious sample preparation steps and GC-MS requires a complicated sample derivatization step which makes the method more time consuming and expensive $[15,16]$. Hence, use of LC-MS/MS for analyzing steroids is a feasible approach as the sample preparation step involved is facile, economical and does not require any additional derivatization step. Compared to previous methods for detecting steroids in environmental waters [15,17-19], the major advantage of our method is that less volume (only $5 \mathrm{~mL}$, opposed to up to $1000 \mathrm{~mL}$ ) of water sample is required for analysis. Another advantage includes the use of liquid-liquid extraction for purification of water samples, which is less time consuming and more economical in comparison to the solid phase extraction processes employed in previous studies [15,17-20].

\section{Water analyses results}

No stanozolol was detected in any of the fifteen bottled waters investigated. In three out of six samples from the Danube river, collected since December '09, stanozolol was detected with levels up to $1.82 \mathrm{pg} / \mathrm{mL}$. In contrast, only one sample of urban tap drinking water from Budapest city was found to contain stanozolol at a concentration of $1.19 \mathrm{pg} / \mathrm{mL}$. The results for stanozolol analysis in different water samples are shown in Table 6.

The possible sources of stanozolol entering the river are unknown, but may be from human or animal consumption and excretion of un-metabolized drug or due to accidental discharge of the parent compound. It should be noted that stanozolol was only found once in 


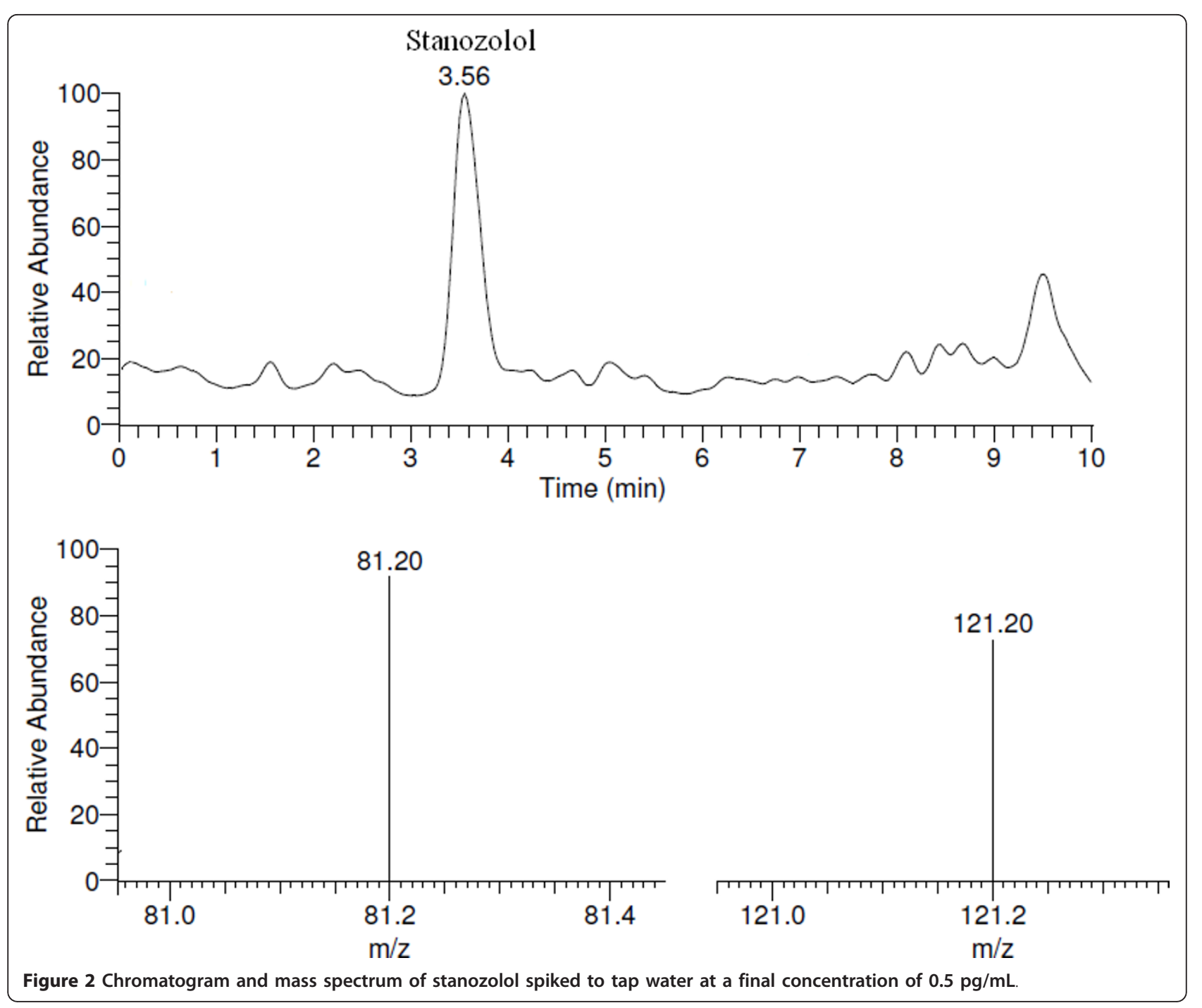

tap water and that this level does not present a threat to health based on recommended intake levels. Water samples from river and tap were collected periodically until November and stanozolol concentrations were found to be reducing over time as shown in Table 5 . The possible reasons for a gradual reduction in concentration could

Table 4 Matrix effect results for stanozolol and stanozolol D3 in HPLC water, tap water and river water

\begin{tabular}{llll}
\hline Matrix & ME $^{\mathbf{1}}(\%)$ & & ME $^{\mathbf{2}}$ (\%) \\
\hline & Stanozolol & Stanozolol D3 (I.S.) & \\
\hline HPLC water $(\mathrm{N}=6)$ & 95.9 & 98.7 & 97.3 \\
Tap water $(\mathrm{N}=6)$ & 88.8 & 92.3 & 96.2 \\
River water $(\mathrm{N}=6)$ & 77.7 & 81.6 & 95.4 \\
\hline
\end{tabular}

$\mathrm{ME}^{1}$ is matrix effect expressed as the ratio of mean peak area of analyte spiked postextraction to the mean peak area of the same analyte standard multiplied by 100 . A value less than 100 indicates ion suppression. $\mathrm{ME}^{2}$ is matrix effect corrected with internal standard. be due to: i) variations in rates of contamination, ii) dilution of river water due to rise in water levels, (see Additional file 1), iii) degradation of the steroid in the river water due to other constituents in the river or photolysis, or deposition in the sediment.

The $\mathrm{pH}$ values of all the river and tap water samples collected were found to be in the neutral range. The $\mathrm{pH}$

Table 5 Extraction recovery of stanozolol (I.S. corrected) at $2 \mathrm{pg} / \mathrm{mL}$

\begin{tabular}{lcc}
\hline Matrix & $\begin{array}{c}\text { Absolute extraction } \\
\text { recovery (\%) }\end{array}$ & $\begin{array}{c}\text { Relative extraction } \\
\text { recovery (\%) }\end{array}$ \\
\hline $\begin{array}{l}\text { HPLC water (N } \\
=6)\end{array}$ & 97.2 & 95.5 \\
Tap water (N & 98.4 & 94.5 \\
$=6$ ) & \\
River water (N & 95.3 & 94.2 \\
$=6)$ & & \\
\hline
\end{tabular}


Table 6 Determination of stanozolol in environmental and domestic water samples

\begin{tabular}{|c|c|c|c|c|c|c|}
\hline \multirow{2}{*}{$\begin{array}{l}\text { Environmental water sample ( } \mathrm{N} \\
=3 \text { ) }\end{array}$} & \multicolumn{6}{|c|}{ Average concentration $\mathrm{pg} / \mathrm{mL}$} \\
\hline & $\begin{array}{l}31^{\text {st }} \text { December } \\
2009\end{array}$ & $\begin{array}{l}18^{\text {th }} \text { April } \\
2010\end{array}$ & $\begin{array}{l}21^{\text {th }} \text { July } \\
2010\end{array}$ & $\begin{array}{l}01^{\text {st }} \text { September } \\
2010\end{array}$ & $\begin{array}{l}24^{\text {th }} \text { October } \\
2010\end{array}$ & $\begin{array}{l}05^{\text {th }} \text { November } \\
2010\end{array}$ \\
\hline River Danube & $1.82 \pm 0.19$ & $0.71 \pm 0.06$ & $0.54 \pm 0.03$ & ND & ND & ND \\
\hline Budapest Tap & $1.19 \pm 0.03$ & 0.31 (BLQ) & ND & ND & ND & ND \\
\hline Lake Balaton & - & ND & - & - & - & - \\
\hline Spring 'Rózsika' & - & ND & - & - & - & - \\
\hline
\end{tabular}

BLQ means below limit of quantification

ND means not detectable

values of bottled water analysed are summarized in Additional file 2. Stanozolol being basic in nature due to the presence of a pyrozole ring is found to be stable in neutral to slightly basic $\mathrm{pH}$. Further investigation needs to be carried out for determining the source of stanozolol and reasons for gradual decrease in its concentration.

In recent years, numerous reports on steroids found in environmental waters have appeared. Stanozolol has been detected (qualitatively) in sludge samples collected from Huiyang and Meihu waste water treatment plants [17]. Chang et al. have also reported the presence of stanozolol in Beijing influent waste water at a concentration of ca. $0.54 \mathrm{pg} / \mathrm{mL}$ [18]. Recently, Tölgyesi et al. have reported the presence of the steroids cortisol, dexamethasone, flumethasone, prednisolone and epitestosterone in Danube river water [15], but their selection of analytes did not include stanozolol.

Our results indicate that stanozolol was present in the River Danube and Budapest tap water in the month of December 2009, when the water level in the river was low (Additional file 2). The National Health Service (NHS) recommends a minimum water intake of 1.2 litres every day [21]. Hence, individuals drinking stanozolol contaminated urban tap water $(1.19 \mathrm{pg} / \mathrm{mL})$ will involuntarily consume approximately $1.43 \mathrm{ng}$ stanozolol per day. Since the effective doses of stanozolol for men and women are 50-100 mgs/day and 2.5-10 mgs/day respectively [22], such low levels detected in drinking water may not cause significant harm to the general public, especially as they were found only at one time point. In addition, a new biological sewage treatment plant opened in July 2010 in Budapest in order to treat most of the water supplied to the city (in contrast to only $30-40 \%$ water being treated in the past). This major environmental protection investment will potentially contribute to a further decrease in levels of stanozolol compared to those we previously observed. Future studies, sampling from various river and tap water sites should, in due course, be able to provide evidence for this.

\section{Conclusions}

In conclusion, a rapid, highly sensitive, robust and reproducible method has been developed to detect stanozolol in different types of water samples. The assay is capable of detecting stanozolol at a concentration as low as $0.25 \mathrm{pg} / \mathrm{mL}$ water when only $5 \mathrm{~mL}$ water is processed. The performance of this method gives acceptable relative recoveries for stanozolol river and tap water samples. The method can be extended to detect other chemicals and pharmaceutical drugs which may be hazardous to human health and environment.

\section{Additional material}

Additional file 1: Danube water level. The supporting document reports the water level, volume, and temperature of River Danube from December 2009 to November 2010.

Additional file 2: Details of bottled drinking water analysed. The supporting document reports the $\mathrm{pH}$, EU recognition and origin of the bottled natural mineral water analysed.

\section{Acknowledgements}

The authors thank Julian Swinden and IItaf Shah for technical advice and help; IP and FP for sample collection. The photos were taken by FP and ZsB.

\section{Author details}

${ }^{1}$ School of Pharmacy and Chemistry, Kingston University, London, UK.

${ }^{2}$ School of Life Sciences, Kingston University, London, UK.

\section{Authors' contributions}

DPN initiated and all authors designed the study. The extraction and method developments were conducted by NIKD who prepared the draft paper. All authors contributed to data analyses and to finalizing the manuscript. All authors have read and approved the final version.

\section{Competing interests}

The authors declare that they have no competing interests.

Received: 17 June 2011 Accepted: 14 October 2011

Published: 14 October 2011

\section{References}

1. Rodriguez-Mozaz S, Weinberg S: Meeting report: pharmaceuticals in water-An interdisciplinary approach to a public health challenge. Environ Health Perspect 2010, 118(7):1010-1020. 
2. Costanzo S, Murby J, Bates J: Ecosystem response to antibiotics entering the aquatic environment. Mar Pollut Bull 2005, 51:218-223.

3. Ternes TA: Occurrence of drugs in German sewage treatment plants and rivers. Water Res 1998, 32:3245-3268.

4. Ye Z, Weinberg HS, Meyer MT: Trace analysis of trimethoprim and sulfonamide, macrolide, quinolone, and tetracycline antibiotics in chlorinated drinking water using liquid chromatography electrospray tandem mass spectrometry. Anal Chem 2007, 79:1135-1144.

5. Heberer T: Occurrence, fate, and removal of pharmaceutical residues in the aquatic environment: a review of recent research data. Toxicol Lett 2002, 131:5-17.

6. Glassmeyer S, Koplin D, Furlong E, Focazio M: Environmental presence and persistence of pharmaceuticals: an overview. In Fate of Pharmaceuticals in the Environment and in Water Treatment Systems. Edited by: Aga DS. Boca Raton, FL: CRC Press, Taylor and Francis Books; 2008:3-51.

7. Daughton CG, Ternes TA: Pharmaceuticals and personal care products in the environment: agents of subtle change? Environ Health Perspect 1999, 107(6):907-938.

8. World Anti-Doping Agency: The 2011 Prohibited List.[http://www.wadaama.org/Documents/World_Anti-Doping_Program/WADP-Prohibited-list/ To_be_effective/WADA_Prohibited_List_2011_EN.pdf], [accessed on 11.06.2011].

9. World Anti-Doping Agency: Laboratory statistics.[http://www.wada-ama org/rtecontent/document/WADA_2008_LaboratoryStatisticsReport_Final. pdf], [accessed on 09.06.2011].

10. Poelmans S, Wasch KD, De Brabander HF, Van De Wiele M, Courtheyn D: Analytical possibilities for the detection of stanozolol and its metabolites. Anal Chim Acta 2002, 473:39-47.

11. World Anti-Doping Agency: Technical Document - TD2010MRPL.[http:// www.wada-ama.org/Documents/World_Anti-Doping_Program/WADP-ISLaboratories/WADA_TD2010MRPLV1.0_Minimum\%20Required\% 20Performance\%20Levels_Sept\%2001\%202010_EN.pdf], [accessed on 10.06.2011].

12. Petróczi A, Aidman EV, Hussain I, Deshmukh N, Nepusz T, Uvacsek M, Tóth M, Barker J, Naughton DP: Virtue or Pretense? Looking behind SelfDeclared Innocence in Doping. PLoS One 2010, 5(5):11.

13. Deshmukh N, Hussain I, Barker J, Petroczi A, Naughton DP: Analysis of anabolic steroids in human hair using LC-MS/MS. Steroids 2010, 75(10):710-714.

14. List of natural mineral waters recognised by member states. [http://ec. europa.eu/food/food/labellingnutrition/water/mw_eulist_en.pdf], [accessed on 09.06 .2011$]$.

15. Tölgyesi A, Verebey Z, Sharma VK, Kovacsics L, Fekete J: Simultaneous determination of corticosteroids, androgens, and progesterone in river water by liquid chromatography-tandem mass spectrometry. Chemosphere 2010, 78:972-979.

16. Kushnir MM, Rockwood AL, Roberts WL, Yue B, Bergquist J, Meikle AW: Liquid chromatography tandem mass spectrometry for analysis of steroids in clinical laboratories. Clin Biochem 2011, 45(1):77-88.

17. Liu S, Ying GG, Zhao JL, Chen F, Yang B, Zhou L, Lai HJ: Trace analysis of 28 steroids in surface water, wastewater and sludge samples by rapid resolution liquid chromatography-electrospray ionization tandem mass spectrometry. J Chromatogr A 2011, 1218(10):1367-1378.

18. Chang H, Wan Y, Wu S, Fan Z, Hu J: Occurrence of androgens and progestogens in wastewater treatment plants and receiving river waters: Comparison to estrogens. Water Res 2011, 45(2):732-740

19. Chang H, Wu S, Hu J, Asami M, Kunikane S: Trace analysis of androgens and progestogens in environmental waters by ultra-performance liquid chromatography-electrospray tandem mass spectrometry. J Chromatogr A 2008, 1195:44-51.

20. Chang $\mathrm{H}$, Wan $\mathrm{Y}, \mathrm{Hu} \mathrm{J}$ : Determination and source apportionment of five classes of steroid hormones in urban rivers. Environ Sci Technol 2009, 43:7691-7698.

21. NHS: A balanced diet.[http://www.nhs.uk/Conditions/Diet/Pages/Fluids. aspx], [accessed on 09.06.2011].

22. Steroid: Winstrol.[http://www.steroid.com/Winstrol.php], [accessed on 09.06.2011].

doi:10.1186/1752-153X-5-63

Cite this article as: Deshmukh et al.: Detection of stanozolol in environmental waters using liquid chromatography tandem mass spectrometry. Chemistry Central Journal 2011 5:63.

\section{Publish with ChemistryCentral and every scientist can read your work free of charge \\ "Open access provides opportunities to our colleagues in other parts of the globe, by allowing anyone to view the content free of charge." \\ W. Jeffery Hurst, The Hershey Company.}

- available free of charge to the entire scientific community

- peer reviewed and published immediately upon acceptance

- cited in PubMed and archived on PubMed Central

- yours - you keep the copyright

Submit your manuscript here:

http://www.chemistrycentral.com/manuscript/<smiles>c1ccccc1</smiles>

Chemistry Centra 